\title{
Giant Multi-Compartmental Trigeminal Neurinoma in a Child: A Case Report
}

\author{
Ishwar Singh* Vinit Bhai and Nisha Marwah
}

Department of Neurosurgery, Pt. B.D. Sharma University of Health Sciences, Rohtak, India

\begin{abstract}
We report a case of solitary giant multi-compartmental trigeminal neurinoma in a 10 year old female child, without the stigmata of neurofibromatosis. The child presented with headache, vomiting, dysarthria, diplopia and altered sensorium.Neuroimaging revealed a giant multi-compartmental trigeminal neurinoma measuring $6.8 \times 4.3 \times 4.0 \mathrm{~cm}$ in size. The tumor was successfully removed by single stage petrosal approach. It is extremely rare for a solitary giant neurinoma to occur at this site in a child without neurofibromatosis. Advantages of petrosal approach in such type of tumor are discussed. As per author's knowledge, this is the largest trigeminal neurinoma reported till date in a child.
\end{abstract}

Keywords: Child, petrosal approach, trigeminal neurinoma.

\section{INTRODUCTION}

Neurinoma's arising from trigeminal nerve are rare tumors, though they are second most common after acoustic neurinomas [1]. Their incidence ranges from $0.07 \%$ to $0.36 \%$ among all intra-cranial tumors and $0.8 \%$ to $8 \%$ of all intracranial neurinomas [2]. They are commonly seen in the 4th and 5th decades. However a solitary neurinoma at this site in a child without neurofibromatosis is a rare occurrence [2-4]. Only a few case reports of small sized solitary neurinomas in children without neurofibromatosis are reported in the literature [2-5]. We report a rare case of a giant multicompartmental trigeminal neurinoma without neurofibromatosis in a child that was completely excised by single stage petrosal approach, with good neurological recovery.

\section{CASE REPORT}

A 10 year old female child, presented with headache associated with vomiting for the last 3 months. She gradually developed numbness of left side of face with dysarthria, ataxia and diplopia. She became drowsy 3 days prior to hospitalization. On examination there was complete sensory and motor paralysis of the 5th cranial nerve with partial involvement of $3 \mathrm{rd}, 4^{\text {th }}$ and $6^{\text {th }}$ to 11 th cranial nerves of the left side. Bilateral papilloedema, bilateral long tract signs and left sided cerebellar signs were also present. She did not have any cutaneous manifestation of neurofibromatosis such as café au lait spots or subcutaneous nodules. There was no family history suggestive of familial neurofibromatosis.Neuroimaging revealed markedly enhancing extra-axial mass of size $(6.8 \times 4.3 \times 4.0 \mathrm{~cm})$ involving left parasellar area, petrous apex, cerebello-pontine and cerebello-medullary angles, with obstructive hydrocephalus, suggestive of trigeminal neurinoma (Fig. 1).

Urgent right sided VP shunt was done to relieve the features of hydrocephalus. The patient's sensorium improved

*Address correspondence to these authors at the Department of Neurosurgery, Pt. B.D. Sharma University of Health Sciences, Rohtak, India; Tel: 01262-274200; Fax: 01262-211308; E-mail: drishwarsingh@yahoo.co.in

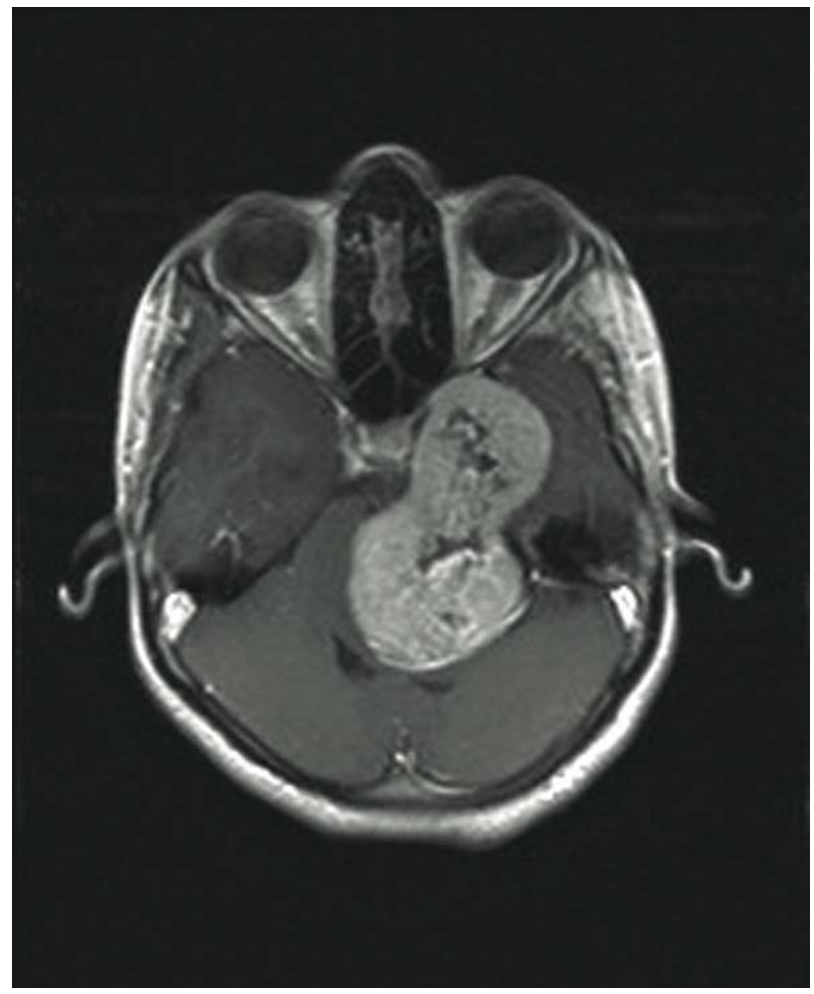

Fig. (1). Gad enhanced MRI revealing giant multi-compartmental Trigeminal neurinoma, axial section.

after the shunt surgery. Later on the trigeminal neurinoma was completely excised via the petrosal approach [6]. The tumor was moderately vascular and soft to firm in consistency. It was gradually debulked using bipolar cautery, suction and curette till the interface between the capsule and the surrounding neurovascular structures was identified. Capsule was then gradually separated from the brain stem and the cranial nerves. Lastly, the tumor was removed from the roof and the lateral wall of the cavernous sinus to ensure complete removal. Postoperative MRI confirmed complete removal of tumors (Fig. 2). Histopathological evaluation of the 
lesion revealed a spindle cell neoplasm with cells arranged in compact fascicles (Antoni A areas) and intervening loosely arranged cells (Antoni B areas). Cellular palisading with formation of Verrocay bodies was evident at places. The tumor was richly vascular with focal perivascular hyalinisation (Fig. 3). Immunohistochemically, the tumor was positive for S-100 protein confirmed the diagnosis of Schwannoma. Patient showed complete neurological recovery at 6 month's follow-up except for persistent $50 \%$ sensory loss in V2 component of 5th cranial nerve.

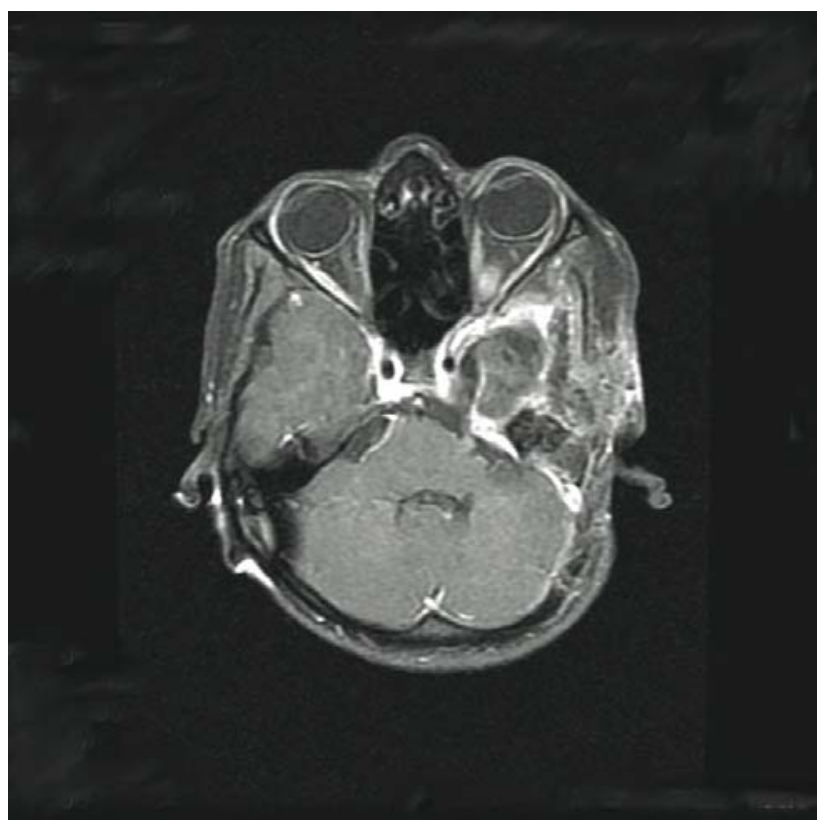

Fig. (2). Post op Gad enhanced MRI revealing complete excision, axial section.

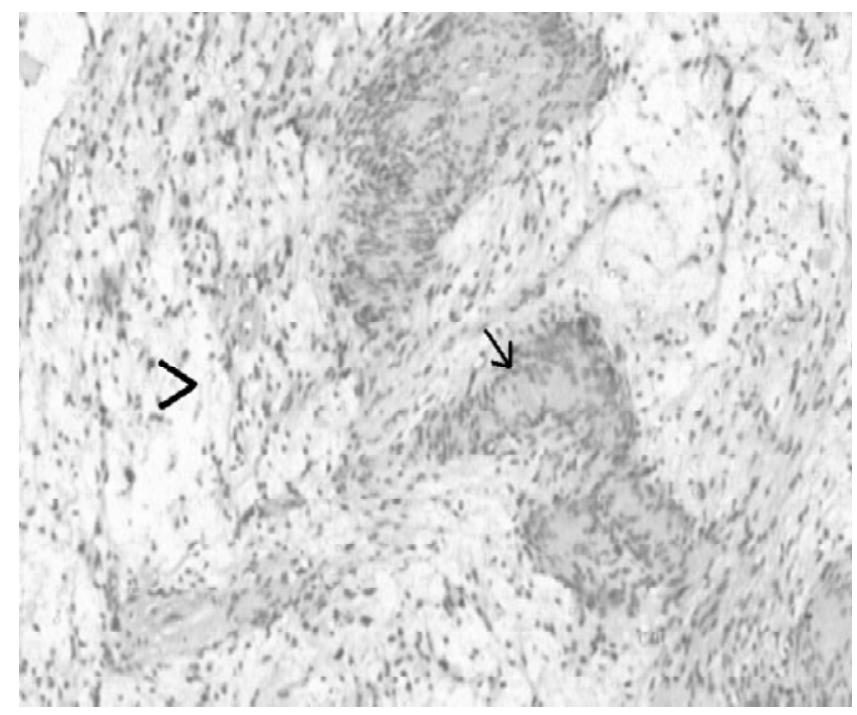

Fig. (3). Microphotograph showing neurinoma with Antoni A(arrow) and Antoni B areas(arrowhead). (H \& E x 100x).

\section{DISCUSSION}

Trigeminal neurinoma is an uncommon tumor and is usually seen in association with multiple intra-cranial neuri- nomas as a manifestation of neurofibromatosis [2]. It is mostly seen between 4th and 5th decades of life with slightly female preponderance [2]. The sensory symptoms in distribution of the trigeminal nerve are the commonest presentation $[1,2,7]$. Other signs and symptoms are produced as per size and location of the tumor. Trigeminal neurinoma is classified into six types according to the tumor location [2, 8]. Type $\mathrm{M}, \mathrm{P}$ and $\mathrm{E}$ represent middle fossa, posterior fossa and extra cranial space respectively; type MP (middle fossa and posterior fossa), ME (middle fossa and extra cranial space) and MPE (middle fossa, posterior fossa and extra cranial space) are tumors involving multiple compartments. Surgical approach to these tumors depends upon their anatomical location. Hence accurate pre-operative delineation of the tumor mass is essential. Multi-compartmental tumors are removed by different combined approaches $[7,9,10]$. The tumor that straddle the middle and posterior cranial fossae and do not extend below the internal auditory canal can be removed through a middle fossa approach $[2,11]$. The combined approach is employed for large dumbbell shaped tumors that extend ventral to the lower brainstem and below the internal acoustic meatus [2, 11]. Various reports have stressed the need for radical surgery so as to achieve higher cure rates. Moreover the recurrence rate with partial resection is reported to be higher in trigeminal neurinoma than acoustic neurinoma [10]. Major impediment to complete removal is inadequate exposure due to deep location of the tumor and close proximity to vital neuro-vascular structures. The ideal surgical approach should be shortest and direct as well as wide and low so as to avoid the need for prolonged and excessive brain retraction.Verstappen et al. [11] reported a case of trigeminal neurinoma of maximum diameter of $53 \mathrm{~mm}$, centered over Meckel's cave in a 6 year old girl removed by single stage pterional approach. However with pterional approach it is difficult to remove large posterior fossa component as was in our case. Moreover pterional approach requires a lot of temporal lobe retraction leading to increased postoperative morbidity. In our patient, a giant multi compartmental trigeminal neurinoma with a large posterior fossa component was completely removed in a single stage using petrosal approach. This combined approach has following advantages:-

1) Cerebellar and temporal lobes are retracted minimally

2) Operative distance to the tumor is less

3) Surgeon not only has direct line of sight to the lesion, but also of the anterior and lateral aspect of the brainstem

4) Neural and the otological structure including the facial nerve, cochlea and labyrinth are preserved

5) The transverse and sigmoid sinus along with the vein of labbe and basal veins are preserved

6) Tumor supply is interrupted early in the procedure

7) Multiple axes of dissection are available.

Injury to the trigeminal nerve is universal and nearly always inevitable, but nontraumatic microsurgical dissection of fibers that are not incorporated in the tumor might even preserve or improve trigeminal nerve function [9, 11]. Our patient had complete trigeminal nerve paralysis which was improved except for $50 \%$ sensory loss in $\mathrm{v} 2$ component. 


\section{CONCLUSION}

Trigeminal neurinoma is very rarely reported in children. Although several multi-staged strategies have been reported in the past, the large tumor in our case was completely excised by single stage petrosal approach, with good neurological recovery.

\section{REFERENCES}

[1] Post KD, McCormick PC. In: Wilkins RH, Rengachary SS, Eds. Trigeminal schwannomas. New York: McGraw-Hill 1996; pp. 1545-52.

[2] Srivastva RK, Sen C, Post KD. In: Winn HR, Eds. Trigeminal schwannomas. Philadelphia: Saunders 2004; pp. 1343-50.

[3] Ross DL, Tew JM , Benton C, Eisentrout C. Trigeminal schwannoma in a child. Neurosurgery 1984; 15: 108-10.

[4] Tsuboi K, Fujimori H, Tomono Y, Hamano K, Nose T. Dumbbell trigeminal schwannoma in a child. Acta Neurochir 1999; 141: 42933.
[5] Perez-Diaz CJ, Villarejo FJ, Pascual AM. Trigeminal neurinoma in infants: report of two cases. Childs Nerv Syst 1996; 12: 283-7.

[6] Al-Mefty O, Fox JL, Smith RR. Petrosal approach for petroclival meningiomas. Neurosurgery $1988 ; 22: 510-17$.

[7] Goel A, Muzumdar D, Raman C. Trigeminal neurinoma: Analysis of surgical experience with 73 cases. Neurosurgery 2003; 52: 78390.

[8] Yasui T, Hakuba A, Kim SH, Nishimura S. Trigeminal Schwannomas.Operative approach in eight cases. J Neurosurg 1989; 71: 506-11.

[9] Al-Mefty O, Ayoubi S, Gaber E. Trigeminal schwanoma: removal of dumbbell-shaped tumors through the expanded Meckel cave and outcomes of cranial nerve function. J Neurosurg 2002; 96: 453-63.

[10] Goel A, Muzumdar D. In: Ramamurthi R, Sridhar K, Vasudevan MC, Eds. Approach to the lateral skull base. New Delhi: BI publication 2005; pp. 1167-95.

[11] Verstappen CCP, Beems T, Erasmus T, Lindert EJV. Dumbbell trigeminal schwannoma in a child: complete removal by one stage pterional surgical approach. Childs Nerv Syst 2005; 21: 1008-11.

Received: February 02, 2011

Revised: March 25, 2011

Accepted: March 30, 2011

(C) Singh et al.; Licensee Bentham Open.

This is an open access article licensed under the terms of the Creative Commons Attribution Non-Commercial License (http://creativecommons.org/licenses/by-nc/3.0/) which permits unrestricted, non-commercial use, distribution and reproduction in any medium, provided the work is properly cited. 